\title{
NOTAS SOBRE O MARAVILHAMENTO NOS CRONISTAS E VIAJANTES COLONIAIS
}

Carlos Alberto Dória 
RESUMO O artigo pretende fazer uma breve apresentação em forma de notas sobre uma bibliografia selecionada que contém as impressões dos cronistas e viajantes sobre o fantástico e o maravilhoso na América Colonial. Tais produções simbólicas não são apenas a documentação do Novo Mundo, mas também se colocam como uma literatura ficcional que compreende determinadas maneiras de apreender o desconhecido.

BESTIÁRIOS • VIAJANTES

- LITERATURA DE VIAGENS • MARAVILHOSO.

\section{NOTES ABOUT THE WONDERFUL IN THE COLONIAL CHRONICLERS AND COLONIAL TRAVELERS}

ABSTRACT The article intends to make a brief presentation in the form of notes on a selected bibliography containing the impressions of chroniclers and travelers on the fantastic and the wonderful in Colonial America. Such symbolic productions are not only the documentation of the New World, but also stand as a fictional literature which comprises certain ways of apprehending the unknown.

BESTIARIES - TRAVELERS

- TRAVEL LITERATURE • WONDERFUL.

\section{SOBRE 0 AUTOR}

Carlos Alberto Dória, nascido em São Paulo, formou-se em Ciências Sociais pela USP, em 1972, e foi professor de Antropologia na Escola de Sociologia e Política de São Paulo. É colaborador regular da revista cultural Trópico, na qual tem publicado artigos como "A Complexidade do Racismo Brasileiro”, "Os Obstáculos da Lei Rouanet” e "Editoras: Do Arcaico ao Grande Capital”, entre outras produções. 
Permitam-me algumas reflexões a título de introdução a uma bibliografia sobre os relatos ditos "fantásticos" de cronistas e viajantes coloniais, constituindo um corpus sobre o qual, entendo, deva-se modificar o modo de entendimento.

\section{I}

Há uma certa semelhança entre o delírio de Brás Cubas, viajando em um hipopótamo - quando pergunta "Onde estamos?” e obtém como resposta "Já passamos o Éden” - e o modo como Gabriel Soares de Sousa (1587) justifica seu relato histórico: "Como todas as coisas têm fim, convém que tenham princípio...”. O ponto de contato é essa sensação, em

RUGENDAS, Johann Moritz.

Viagem Pitoresca Através do Brasil.

1989, p. 97. 
nossa literatura, de que algo importante ficou para trás e que justifica a “teoria do achamento" da nossa expressão que Jorge de Lima formula no ensaio “Todos Cantam a Sua Terra” (1929). E um movimento de recuperação do passado pode ser surpreendido a partir das décadas de 1830-1840 na nossa literatura romântica, especialmente nos folhetins dos jornais, nos quais os autores dialogam com uma forma literária que é o relato de viagem. Ora, é exatamente no relato de um desses viajantes, Jean de Léry, que leremos: “[...] depois de minha viagem à America. [...] Devo confessar que, embora não aceitando como verdadeiras as fábulas encontradiças em vários autores [...] vi coisas tão prodigiosas quanto tantas outras tidas por impossíveis". O que queremos discutir aqui é essa noção de "prodígio" ou "impossibilidade" e talvez o melhor atestado de "prodígios" ou coisas que pareciam impossíveis sejam os antigos bestiários. Nesta concepção plural, todos eles teriam se originado a partir de um hipotético Physiologus que se perdeu no tempo e foi se transformando, tendo como base diversas compilações de fontes escritas e orais. Entre nós, não houve tempo ainda para se formar a tradição de compilação, de sorte que o "bestiário" se oferece mais como gênero literário do que como ilustração histórica de um modo hoje desusado de descrever o mundo. Hoje o aspecto mais importante dos bestiários conhecidos é a maneira como, com o tempo, passaram a ser considerados. Suas fontes remontam aos Pais da Igreja, à Grécia, ao Egito, às mitologias ocidentais e orientais. Assim, refletem não só fontes orais filiadas a várias tradições culturais como também escritos de Aristóteles e Plínio. O surgimento do Physiologus entre os séculos II e v, provavelmente no Egito ou na Grécia, a partir de quando foi traduzido ao siríaco, armênio, etíope e latim, conferiu a esta tradição cultural uma difusão talvez só superada pela Bíblia. Evidentemente cada nova tradução ensejava novas agregações. Por exemplo, é sabido que a versão grega do Physiologus apresentava 59 bestas, mas uma versão posterior, também em grego, encontrada em 1724, apresentava 150 bestas. Os bestiários constituíam o epicentro de forças centrípetas que faziam gravitar em torno de um mesmo eixo os conhecimentos do mundo animado. Tigres, elefantes, panteras, unicórnios, grifos, hienas, macacos, sátiros, salamandras, serpentes voadoras - são seres que deixaram, indistintamente, seu registro nos bestiários. Assim, aos poucos, de "tratados" de biologia tornaram-se repositório ou coleção de seres que de alguma maneira podiam ser classificados juntos por aspectos externos coincidentes, por princípios geracionais ou quaisquer outros parentescos que os viajantes a terras distantes iam reunido para compor sua aparência.

Ora, os bestiários medievais podem ser agrupados segundo as várias categorias de bestas. O bestiário telúrico (elefante, tigre, castor etc.); 
o bestiário aquático (cisne, ostra, baleia, delfim); bestiário aéreo (águia, grifo, íbis, avestruz, camaleão); bestiário ígnio (fênix e salamandra) e, finalmente, monstros e híbridos. Essa forma de classificação era já distinta daquela consagrada por Aristóteles, que considerava a forma de reprodução dos animais como a melhor possibilidade de agrupá-los: vivíparos; ovíparos; os que punham ovos imperfeitos como os peixes, cujos ovos crescem após postos; os que procedem de um verme; os que nascem por geração espontânea, como os moluscos. William Harvey, que publicou seu De Generatione Animalium em 1651, repousou sobre a doutrina aristotélica a ideia de atribuir a epigênese à evolução ou desenvolvimento do ovo, isto é, a formação sucessiva das diferentes partes cujo conjunto constitui o todo orgânico. O testemunho dos bestiários constituiu, ainda por longo tempo, uma grande interrogação para o pensamento racional em vias de se firmar.

A classificação dos animais segundo os quatro elementos deixava de fora as monstruosidades e os seres que, aparentemente, representavam a convergência de características de mais de uma espécie ou grupo. O pensamento religioso procurou, ao seu modo, ajustar essa percepção do mundo ao firmar-se na convicção de que na arca de Noé apenas espécies puras foram embarcadas, ficando as monstruosas ou híbridas presas às trevas do passado. No entanto, foi no século XVIII que essa maneira de interpretar o mundo começou a ruir efetivamente. Até então prevaleceu a ideia de que Deus, Supremo Artesão, havia criado cada ser vivente individualmente, que havia se ocupado do mais insignificante inseto da maneira mais atenta. Essa forma de apologia da história natural divina encontra-se consagrada no Spectacle de la Nature do Abade Noël Pluche, obra em nove volumes aparecida entre 1732 e 1750 e que constituiu, na França, um dos grandes sucessos literários do século. Mas o Conde de Buffon, o jardineiro- cientista do rei, escreveu na mesma época sua monumental Histoire Naturelle trazendo a razão para o centro da história e da vida, calculando a idade da Terra sem considerar os textos bíblicos e afirmando que as espécies vivas não eram imutáveis. E deve-se a Carolus Linnaeus o sistema de classificação de todas as plantas e animais conhecidos atribuindo-lhes um nome científico, ou melhor, duas palavras latinas a cada um: um expressando o gênero a que pertence e, outro, a espécie. Linnaeus se interessou pela classificação dos seres vivos ao estudar as flores por seus pistilos, conforme se lê em seu Species Plantarum (1753), sendo que a décima edição de seu Systema Naturae (1758) encerra a classificação de mais de quatro mil animais, inclusive os seres humanos - pela primeira vez denominados pelo nome científico de Homo sapiens. 


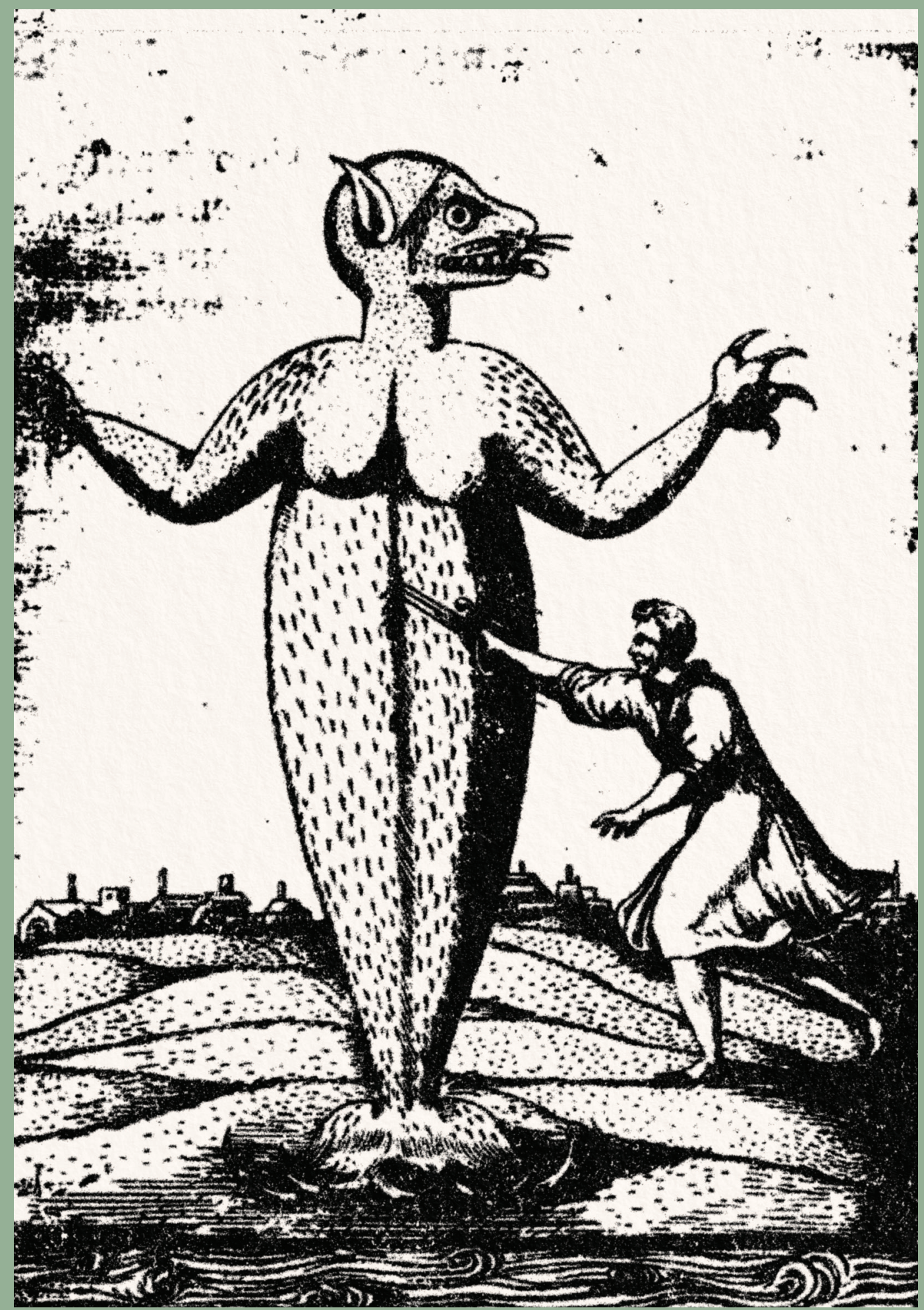


A dinastia Habsburgo (Casa de Áustria) - entre 1516 e a ascensão dos Bourbons em 1700 - cultiva as "sevandijas palaciegas, a gente de placer, a bufonería”, depois desterrada pelos Bourbons. Somente os nobres podiam se entreter com esses seres estranhos, num misto de rechaço e fascinação. Eram compostos por anões, loucos reais e "fingidos", loco e loquillos bobos, gigantes, deformados etc. Essa coleção de prodígios revelava a diretriz de buscar seres impossíveis para os palácios, em teoria elegantes e circunspectos. "Seres que por sua imperfeição foram a exceção que ressaltava a dignitas que devia imperar na corte real, último e perfeito círculo de uma sociedade que imaginava a si própria bem ordenada e harmonicamente construída". Seres monstruosos que fizeram possível que "entre demasia e falta se divisasse melhor a formosura e proporção do que é banal", segundo o jesuíta Juan Eusebio Nieremberg, no seu livro Curiosa y Oculta Filosofía (Madrid, 1643). É bem provável que o Ipupiara, monstro marinho descrito por Pero de Magalhães Gândavo e que foi morto por Baltazar Ferreira, poderia de encaixar nessa coleção de sevandijas de palácio. Jean de Léry também o descreve, segundo o relato de um selvagem:

Surgiu um grande peixe que segurou a embarcação com as garras procurando virá-la ou meter-se dentro dela. Vendo isso, decepei-lhe a mão com uma foice e a mão caiu dentro do barco e vimos que tinha cinco dedos como a de um homem. E o monstro, excitado pela dor pôs a cabeça fora d'água e a cabeça que era de forma humana, soltou um pequeno gemido [...].

Ao que acrescenta um comentarista moderno: devia ser um leão marinho. Mas é só no século XIX que aparece o nome enganosamente indígena de uiara ou iara, romanticamente imaginada como uma versão tropical e indígena das janas, nixes e loreleis do folclore europeu. A América, então, era um território de "anomalias", de seres que o europeu cuidou de registrar ao longo de séculos, só sendo compilados nos anos 1930 pelo Visconde de Taunay. 


\section{III}

Por outro lado, para que o leitor não se perca no emaranhado que vai se tecendo, para que possa entrar ou sair desse domínio por portas de acesso mais seguras, tudo pode ser arranjado e apresentado como uma miscelânea, uma botânica e uma geografia fantástica, além de um "bestiário" propriamente dito. Porém quaisquer que venham a ser as escolhas do leitor não poderá ele desprezar a visão do passado colonial de que somos portadores. Gândavo, por exemplo, escreveu em 1576 “os segredos da natureza não foram revelados todos ao homem, para que com razão possam negar e ter por impossível as coisas que não viu nem de que nunca teve notícia”. Com isso, ele queria preparar os espíritos europeus para a incredulidade que necessariamente protege a razão do contato com o inusitado. Essa proteção se apoia justamente na ideia de "revelação", isto é, no fato de que tudo que é conhecido obedece a desígnios divinos e o que é ocultado também. Assim, a descoberta do novo ou reafirma o divino ou, ao contrário, atende a desígnios diabólicos. E como discriminar qual o arquiteto maior de nossa percepção quando estamos diante do inusitado? Ora, há quinhentos anos acreditamos viver em um novo mundo que, a nós ocidentais, estranha a cada

1 THEVET, Singularidades da França Antarctica, reproduzida in TAUNAY, Affonso de E. Zoologia Fantástica do Brasil. [1934], p. 90.

2 THEVET, Singularidades da França Antarctica, reproduzida in TAUNAY, Affonso de E. Zoologia Fantástica do Brasil. [1934], p. 90.

3 THEVET, Singularidades da França Antarctica, reproduzida in TAUNAY, Affonso de E. Zoologia Fantástica do Brasil. [1934], p. 89.

4 THEVET, Singularidades da França Antarctica, reproduzida in TAUNAY,

Affonso de E. Zoologia do Brasil. [1934], p. 89. 

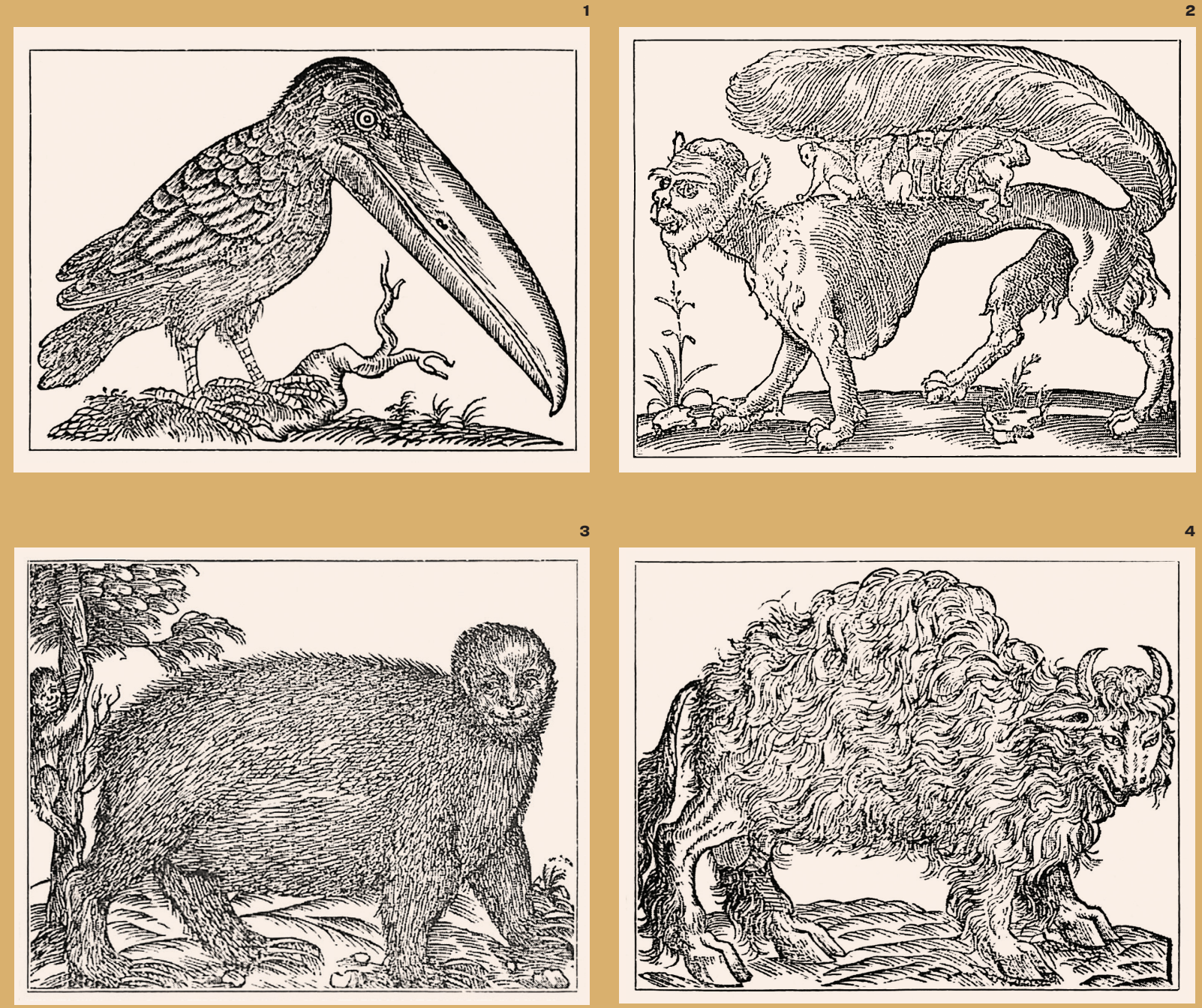
momento. É como uma caixa de segredos não totalmente desvendados e, nesse sentido, o mundo novo ainda não é totalmente nossa terra, nossa empresa. Achamos, ao contrário, que um país se faz aos poucos (e poderíamos acrescentar que se desfaz no mesmo ritmo). Portanto a história colonial, antes de ser dos homens, é a história do território. É a história natural. Nessa linha de percepção do novo mundo, registrou o jesuíta Manoel da Nóbrega, em 1549: “É de grande maravilha haver Deus entregue terra tão boa, tamanho tempo, a gente tão inculta que tão pouco o conhece, porque nenhum Deus tem certo, e qualquer que lhes diga ser Deus o acreditam”. Assim, os “contos naturais”, que podem ser reunidos a partir dos relatos de cronistas e viajantes, se assemelham a um livro de cabeceira com seu papel primordial: guia de sonhos, pesadelos, guia de suas aleatórias produções. Por certo quem busca a razão evita o que a perturba e o imaginário pertence ao domínio da noite, em contraste com o dia que pertence ao trabalho, à razão.

Pelo imaginário buscamos trânsitos que nos permitam desembarcar no contemporâneo transformado. O homem que desembarcou na América logo percebeu que o desejo da nova terra, em sua pujança, era ser desejada. Gândavo escreveu: “que floresça tanto a terra desta nova Lusitânia, e seja dos outros invejada para que não desejemos terras estranhas”. Essa é a viagem que se propõe através de uma coletânea do fantástico e maravilhoso registrado nesse corpus de relatos.

\section{IV}

Para um autor como Alejo Carpentier, há uma profunda identidade entre linguagem e história, entre literatura e vida. Esse é o seu conceito de real-maravilhoso, isto é, de linguagem poética como expressão das contradições do mundo americano. No ensaio "O Barroco e o Real Maravilhoso" nos propõe:

[...] nossa natureza é indômita, como nossa história, que é a história do real maravilhoso e do insólito na América, e que para mim se manifesta em fatos como estes que vou recordar muito rapidamente: o rei Henri Christophe, do Haiti, cozinheiro que chegou a ser imperador de uma ilha e que imaginando um certo dia em que Napoleão iria reconquistar a Ilha, constrói uma fortaleza fabulosa onde poderia resistir a um assédio de dez anos com todos os seus dignitários, ministros, soldados, tropas, tudo, e tinha armazenadas mercadorias e alimentos, para poder existir dez anos como país independente (falo da cidadela de Laferrière). E para que essa fortaleza tenha paredes que resistam ao ataque dos homens da Europa, faz misturar o cimento com sangue de centenas de touros. A revolta de Mackandal, que leva milhares e milhares de escravos, no Haiti, a crerem 
que possuía poderes licantrópicos, que podia se transformar em ave, que podia se transformar em cavalo, em mariposa, em inseto, no que desejasse, e promove com isso uma das primeiras revoluções autenticas do Novo Mundo. A carruagenzinha negra de Benito Juárez, na qual levava toda a nação mexicana sobre quatro rodas através das estradas do país, sem escritório, sem lugar onde escrever, sem palácios, sem descanso, e a partir dessa pequena carruagem consegue vencer os três imperialismos mais poderosos da época. Juana de Azurduy, a prodigiosa guerrilheira boliviana, precursora de nossa guerra de independência, que um dia tomou uma cidade para resgatar a cabeça do homem amado que estava exposta numa lança, na Praça Central. [...] O fato de que Augusto Comte, fundador do positivismo, tenha hoje templos, onde lhe prestam culto, no Brasil. [...] Finalmente, há personagens muito mais interessantes, de segundo plano, em nossa história do século XIX, personagens que deixam muito atrás de si os pequenos reis escoceses como Macbeth. [...] E se nosso dever é o de revelar este mundo, devemos mostrar, interpretar nossas coisas. E essas coisas se apresentam como coisas novas a nossos olhos. A descrição é inequívoca, e a descrição de um mundo barroco há de ser necessariamente barroca, quer dizer, o quê e o como nesse caso se alinham ante uma realidade barroca ${ }^{1}$.

Seu método de criação possui pressupostos que é interessante registrar aqui:

[...] muitos se esquecem que o maravilhoso começa a sê-lo de maneira inequívoca quando surge de uma inesperada alteração da realidade (o milagre), de uma revelação privilegiada da realidade, de uma iluminação inusual ou singularmente favorecedora das inadvertidas riquezas da realidade, de uma ampliação das escalas e categorias da realidade, percebidas com particular intensidade em virtude de uma exaltação do espírito que o conduz de certa forma a um "estado limite". Para começar, a sensação do maravilhoso pressupõe a fé. Os que não creem em santos não podem se curar através de milagres de santos².

Só com boa dose de arbitrariedade é possível reunir tudo o que pareceu fantástico e fabuloso no sentido da descrição do mundo novo que habitamos. É certo que a preocupação em delimitar o conceito de "fantástico", "mágico", maravilhoso ou "estranho” corresponde a formas que a modernidade encontrou para confinar certos fenômenos num

\footnotetext{
Alejo Carpentier, Ensayos, pp. 123-124.

Idem, p. 77.
} 
outro tempo e espaço, separando a mente racional daquilo que lhe parece impenetrável. A própria fé - o indemonstrável - de que fala Carpentier aparece como "estado limite", fruto de uma exaltação do espírito diante de uma iluminação ou conhecimento inusual. Ora, o que exalta o espírito parece ser a desordem, a antiordem, expressa nas aparições fenomênicas de que os bestiários são apenas um exemplo. Refere-se não só aos seres que se integram ou pertencem aos quatro elementos - terra, mar, ar e fogo - de modo antes nunca visto mas também ao modo de descrever registrado em textos variados que, hoje, são lidos como meros delírios de autores quinhentistas, a setecentistas. Mas como notou Piero Caporesi, que cita Letere Odorose de Lorenzo Magalotti (1693-1705):

O jovial, o gracioso, o gentil, o salubre, o recreativo são prerrogativas da nossa terra da Europa. O nobre, o rico, o aromático, o majestoso, o indistinto, o vital, o admirável existem na América. [...] tudo o que era indígena, tudo o que era cultivado nos jardins, nas hortas, nos campos da Itália, ou que espontaneamente ali crescia, parecia ter perdido o poder de atrair ${ }^{3}$.

E é sem duvida sobre essa "necessidade europeia" que encontram lugar e prosperam as abusões originadas no Novo Mundo - esse "estado limite" nas palavras de Carpentier, em que se apoia a história do real maravilhoso cujo pressuposto é a fé. O modo de acomodar essas aparições do real ao universo racional foi igual aos esforços de todos os tempos para encaixá-los, de algum modo, na racionalidade ocidental. A obra de Afonso d'Escragnolle Taunay (Zoologia Fantástica do Brasil) sem dúvida corresponde a um esforço sistemático para fazê-lo. Depois dele, registrou-se o tratamento de muitas abusões como temas do "folclore", esta "ciência" que cristaliza o insólito como algo que brota no terreno simplório do saber popular, como exageros e distorções que se explicam pelo conhecimento mágico que se forma e consolida distante das ciências.

Nesse sentido é notável o surgimento da revista Abusões, cujo editorial diz:

As artes da abusão: dos erros de percepção, das coisas que se tomam por outras, das ilusões e dos enganos; da crença no fantástico e das superstições; dos feitiços, dos esconjuros e dos malefícios. Foi em torno dessa hoje exótica palavra que nasceu a Abusões, revista dedicada às ficções que transitam nas franjas do real, um projeto que é fruto da parceria entre dois Grupos de 
RUGENDAS, Johann Moritz. Malerische Reise in Brasilien. 1835, folha de rosto.

\section{IEAN DE LÉRY}

HISTOIR E

$D^{\prime} \mathrm{UN}$

VOYAGE FAICT EN LA TERRE DU BRÉSIL NOUVELLE ÉDITION

Avec une Introduction \& des Notes

$$
\text { PAR }
$$

PAUL GAFFAREL

Profeffeur à la Faculté des lettres de Dijon

TOME PREMIER

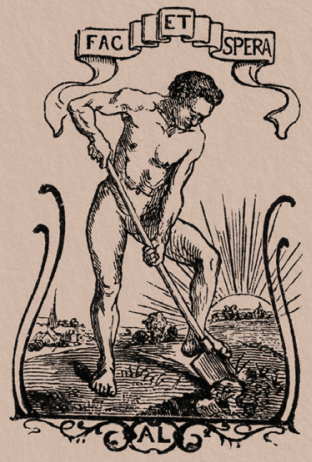

\section{PARIS}

ALPHONSE LEMERRE, ÉDITEUR 27-3I, PASSAGE CHOISEUL, 27-31 -

$M \operatorname{DCCC} \operatorname{Lxx}$

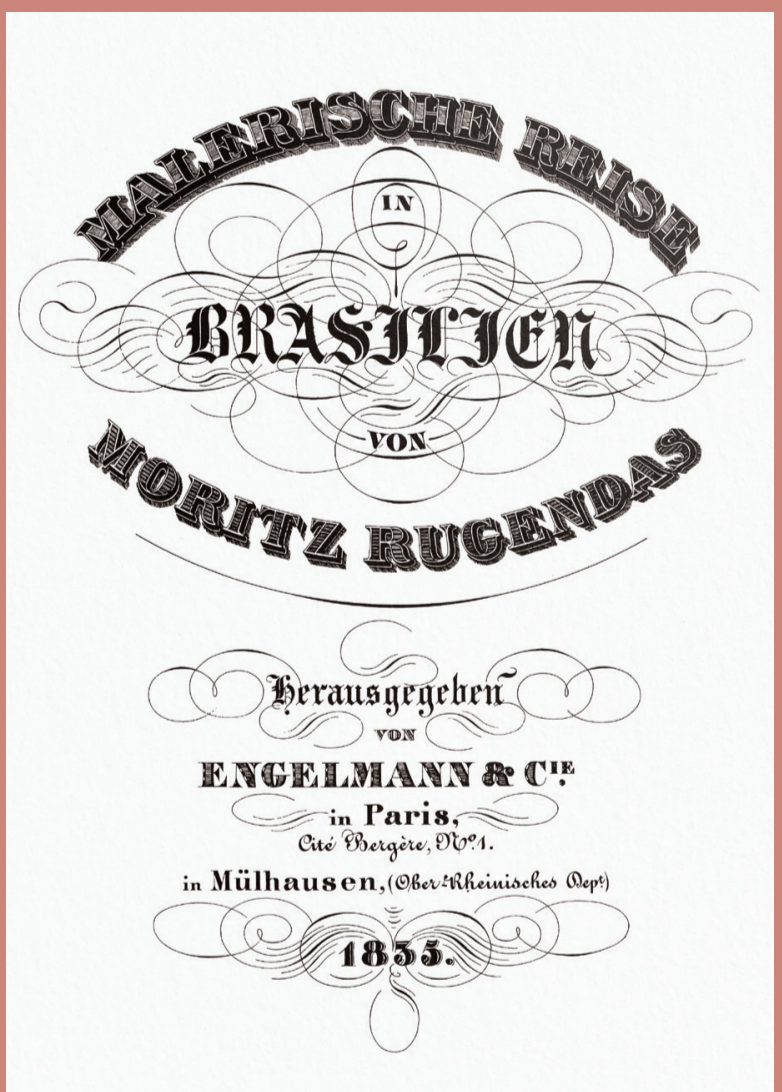

LÉRY, Jean de. Histoire d'un Voyage Faict en la Terre du Brésil; 1880, folha de rosto. 
Pesquisa certificados pela Universidade do Estado do Rio de Janeiro (Uerj) junto ao Diretório de Grupos do Conselho Nacional de Desenvolvimento Científico e Tecnológico (CNPq), o Nós do Insólito: Vertentes da Ficção, da Teoria e da Crítica e o Estudos do Gótico. O vigor desse campo de estudos nas universidades brasileiras é atestado pelo surgimento e consolidação, nos últimos anos, de vários grupos de pesquisa a ele dedicados, como o Vertentes do Fantástico na Literatura (Unesp), o Espacialidades Artísticas (UFU), o Língua e Literatura: Interdisciplinaridade e Docência (Unifesp) e o Narrativa e Insólito (UFU), todos reunidos, juntamente com nossos dois grupos da Uerj, no GT da Associação Nacional de Pós-graduações e Pesquisa em Letras e Linguística Vertentes do Insólito Ficcional. Dessas inúmeras e labirínticas intersecções e tangências entre o insólito, o gótico, o fantástico, o medo, o estranho, o maravilhoso, o horror, a fantasia, o sobrenatural, vêm os artigos que dão corpo à publicação ${ }^{4}$.

Sem dúvida esse novo enquadramento da produção simbólica do sistema colonial poderá mostrar-se rico e fértil para todos quanto lidem com a literatura ficcional, enriquecendo o entendimento do alargamento do espírito humano que inaugura o mundo moderno, a partir dos descobrimentos.

4. Disponível em: http://www.e-publicacoes.uerj.br/index.php/abusoes/about/ editorialPolicies\#focusAndScope. Acesso em: 25 ago. 2017.

\section{REFERÊNCIAS}

Agassiz, Luiz \& Agassiz Elizabeth Cary. Viagem ao Brasil (1865-1866). São Paulo, Nacional, 1938. AIrosa, Plinio Marques da Silva. Apontamentos Para a Bibliografia da Língua Tupi-Guarani. 2a . ed., rev. e atual. São Paulo, Faculdade de Filosofia, 1954.

Almeida PRAdo, João Fernando de. Pernambuco e as Capitanias do Norte do Brasil (1530-1630). São Paulo, Nacional, 1939.

. Fontes Primárias para o Estudo das Explorações e Reconhecimento Geral no Século XVI. Seminário de Estudo das Fontes Primárias para a História de São Paulo no Século Xvi, 1944. Folheto ${ }^{\circ} 21$.

Primeiros Povoadores do Brasil: 1500-1530. São Paulo, Nacional, 1939.

Anchieta, José de. Carta Fazendo Descripção das Inumeras Coisas Naturaes, que se Encontram na Província de São Vicente Hoje São Paulo, Seguida de Outras Cartas Ineditas e Copiadas do Archivo da Companhia de Jesus; trad. do latim pelo professor João Vieira de Almeida, com um prefácio pelo Dr. Augusto Cesar de Miranda Azevedo. Cartas Avulsas: 1550-1568. Rio de Janeiro, Oficina Industrial, 1931.

. Cartas, Informações, Fragmentos Históricos e Sermões do Padre Joseph de Anchieta: 15841586. Rio de Janeiro, Imprensa Nacional, 1886.

. Informação do Brasil e Fragmentos Históricos. Introdução de Capistrano de Abreu. Rio de Janeiro, s.c.p., pref. 1886, XvI.

ARAGÃo, Salvador Pires de Carvalho. Estudos Sobre a Bahia Cabralia e Vera-Cruz Feitos por Ordem do Governador do Estado o Illm. e Exm. Snr. Cons. Luiz Vianna. Bahia, Litho-Typ. e 
Encadernação Reis \& Co., 1899, vi.

. Bibliografia Crítica da Etnologia Brasileira. São Paulo, Comissão do Iv Centenário, Serviço

de Comemorações Culturais.

. Ensaios Sobre Etnologia Brasileira. Prefácio de Affonso de E. Taunay. Edição fac-similar.

São Paulo, Nacional, 1937.

Lendas dos Índios do Brasil: Selecionadas e Comentadas. São Paulo, Brasiliense, 1946.

Tapirapé: Tribo Tupi no Brasil Central. São Paulo, Nacional, Edusp, 1970.

BARIL, V.L., Comte de la Hure. L'Empire du Bresil: Monographie Complete de l'Empire Sud-

Americain. Paris, Ferdinand Sartoris, 1862, xv.

Barroso, Gustavo Dodt. Mythes, Contes et Légendes des Indiens: Folk-lore Bresilien. Paris,

Librairie des Amateurs, 1930, II.

BAYARD, Jean Pierre. História das Lendas. Trad. Jeanne Marillier. São Paulo, Difusão Europeia do Livro, 1957.

BoeHrer, George C. A. Apontamentos Para a Civilização dos Índios Bárbaros do Reino do Brasil por José Bonifácio de Andrada e Silva. Lisboa, Agência Geral do Ultramar, 1963.

CABral, Luis Gonzaga do Vale Coelho Pereira. Jesuítas no Brasil: Século Xvi. São Paulo,

Melhoramentos, 1925. Coleção Inéditos e Dispersos, vol. 3

Calmon, Pedro. História do Brasil: As Origens (1500-1600). São Paulo, Nacional, 1939.

CANDIDo, Antonio Zeferino. Brazil. Rio de Janeiro, Imprensa Nacional, 1900, viII.

CARDim, Fernão. Tratados da Terra e Gente do Brasil. Belo Horizonte/São Paulo, Itatiaia/Edusp, 1980.

CASCudo, Luis da Câmara. Antologia do Folclore Brasileiro, Séculos XVI-XVII-XVIII. $4^{a}$ ed, São

Paulo, Martins, 1971.

. Anubis e Outros Ensaios: Mitologia e Folclore. Rio de Janeiro, O Cruzeiro, 1951.

. Dicionário do Folclore Brasileiro. Prefácio de Antônio Balbino. Rio de Janeiro, INL, 1954, XII.

Geografia dos Mitos Brasileiros. Rio de Janeiro, José Olympio, 1947.

. Geografia dos Mitos Brasileiros. Belo Horizonte/São Paulo, Itatiaia/Edusp, 1983. XXII.

. História dos Nossos Gestos: uma Pesquisa na Mímica do Brasil. São Paulo, Melhoramentos, 1976.

. Superstições e Costumes: Pesquisas e Notas de Etnografia Brasileira. Rio de Janeiro,

Antunes, 1958.

CAStillejo, Federico Fernandez de. La llusión en la Conquista: Génesis de los Mitos y Leyendas

Americanos. Buenos Aires, Atalaya, c. 1945.

Colonelli, Cristina Argenton. Bibliografia do Folclore Brasileiro. São Paulo, 1979. Coleção

Folclore, vol. 19.

Cortes Ão, Jaime. A Carta de Pero Vaz de Caminha. Rio de Janeiro, Livros de Portugal, 1943.

Coleção Clássicos e Contemporâneos.

. Alexandre de Gusmão e o Tratado de Madri. Rio de Janeiro, Ministério das Relações

Exteriores, 1952.

. Antecedentes do Tratado de Madri; Jesuítas e Bandeirantes no Paraguai: 1703-1751.

Introdução, notas e sumário por Jaime Cortesão. Rio de Janeiro, Biblioteca Nacional, 1955.

Manuscritos da Coleção de Angelis, vol. 6.

Cabral e a Origem do Brasil: Ensaio de Topografia Histórica. Rio de Janeiro. Ministério das

Relações Exteriores, 1944.

. A Expedição de Pedro Álvares Cabral e do Descobrimento do Brazil. Lisboa, Ailland, 1922.

. Do Tratado de Madri à Conquista dos Sete Povos: 1750-1802. Introdução, notas e sumário

por Jaime Cortesão. Rio de Janeiro, Biblioteca Nacional, Divisão de Publicações e

Divulgação, 1969. Manuscritos da Coleção de Angelis, vol. 7.

. Jesuítas e Bandeirantes no Guairá: 1549-1640. Introdução, Notas e Glossário por Jaime

Cortesão. Rio de Janeiro, Biblioteca Nacional, 1951. Manuscritos da Coleção de Angelis, vol. 1. . Jesuítas e Bandeirantes no Itatim: 1596-1760. Introdução, Notas e Glossário por Jaime

Cortesão. Rio de Janeiro, Biblioteca Nacional, 1952. Manuscritos da Coleção de Angelis, vol. 2. . Jesuítas e Bandeirantes no Tape: 1615-1641. Introdução e Notas por Jaime Cortesão. Rio de

Janeiro, Biblioteca Nacional, 1969. Manuscritos da Coleção de Angelis, vol. 3. . Portugueses e Índios no Brasil Colonial. São Paulo, ECA, 1972. Série Cultura Geral. 
Tratado de Madri: Antecedentes - Colônia de Sacramento: 1669-1749. Introdução, notas e sumário por Jaime Cortesão. Rio de Janeiro, Biblioteca Nacional, Divisão de Obras Raras e Publicações, 1954. Manuscritos da Coleção de Angelis, vol. 5.

DeBRET, Jean Baptiste. Viagem Pitoresca e Histórica ao Brasil. Trad. Sergio Milliet. Belo Horizonte/ São Paulo, Itatiaia/Edusp, 1978, 2 vols.

Viagem Pitoresca e Histórica ao Brasil. São Paulo, Martins/Edusp, 1972. 2 vols.

D’Evreux, Ivo. Viagens ao Norte do Brasil. Trad. Dr. Cesar Augusto Marques. Rio de Janeiro, Tip. do Anuário do Brasil, 1929. Coleção Bibliotheca dos Escritores Maranhenses, vol. 11.

DıÁLOgos das Grandezas do Brasil, Pela Primeira vez Tirados em Livros. Introdução de Capistrano de Abreu e notas de Rodolpho Garcia. Rio de Janeiro, Officina Industrial Graphica, 1930. Coleção História, vol. 3.

Dieudonné, Marie Joseph Auguste Emmanuel, conde de Las Casas. Atlas Histórico, Genealógico, Cronológico, Geográfico etc., de Lesagne. Escrito por el Conde de Las Casas; Traducido, Corregido y Aumentado por un Español Americano. Paris, Bossange, 1826.

DONNER, Florinda. Shabono. London, Triad/Paladin, 1984.

D’orbignY, Alcide. Viagem Pintoresca Através do Brasil. Trad. David Jardim. Belo Horizonte/São Paulo, Itatiaia/Edusp, 1976.

Ehrenreich, Paul. Anthropologische Studien über die Urbewohner Brasiliens: Vornehmlich der Staaten Matto Grosso, Goyaz und Amazonas (Purus-Gebiet). Vieweg, Brunswick, 1897. . Contribuições Para a Etnologia do Brasil. Trad. Egon Schaden. Introdução e notas de Herbert Baldus. São Paulo, Revista do Museu Paulista, 1948.

EsTóRIAS e Lendas dos Índios. Seleção e introdução de Herbert Baldus. Ilustrações de J. Lanzellotti. Antologia Ilustrada do Folclore Brasileiro. São Paulo, Literart, 1960. Estórias, lendas, vol. I.

FARINHA, António Lourenço. A Expansão da Fé na África e no Brasil (Subsídios Para História Colonial). Lisboa, Attica, 1942, 2 vols.

FERnADES, José Loureiro. Os Índios da Serra dos Dourados: Os Xetá. Recife, Imprensa Universal, 1946.

Florence, Hercules. Viagem Fluvial do Tietê ao Amazonas: de 1825 a 1829. 2ª ed. Trad. Visconde de Taunay. São Paulo, Melhoramentos, 1948.

Freyre, Gilberto de Mello. O Mundo que o Português Criou: Aspectos das Relações Sociais e de Cultura do Brasil com Portugal e as Colônias Portuguesas. Rio de Janeiro, Olympio, 1940.

GÂNDAvo, Pero de Magalhães. História da Província de Santa Cruz. (Publicado com Tratado da Terra do Brasil). Rio de Janeiro, Anuário do Brasil, s.d., pp. 65-147. Coleção Clássicos Brasileiros. . Tratado da Terra do Brasil: História da Província de Santa Cruz. Belo Horizonte/São Paulo, Itatiaia/Edusp, 1980.

Gerber, Raquel. O Mito da Civilização Atlântica: Glauber Rocha, Cinema, Política e a Estética do Inconsciente. Rio de Janeiro, Vozes, 1982.

Gorham, Rex. The Folkway of Brazil: A Bibliography. Compiled by Rex Gorham, Edited by Kart Brown. New York, The New York Public Library, 1944.

Guerreiro, Fernão. Relação Anual das Coisas que Fizeram os Padres da Companhia de Jesus nas Suas Missões do Japão. Nova edição dirigida e prefaciada por Artur Viegas. Coimbra, Imprensa da Universidade, 1930-1931, 2 vols.

GuIDO, Angelo. “Mito das Icamiabas” (Separata). Revista do Instituto Histórico e Geográfico do Rio Grande do Sul, ano XviII, 1ํㅗㄹ semestre 1937.

HARTT, Charles Frederick. Os Mitos Amazônicos da Tartaruga. Tradução e notas de Luis da Câmara Cascudo. Recife, Arquivo Público Estadual, 1952.

HeRmes Jr., João Severino da Fonseca. Limites do Brasil: Descrição Geográfica da Linha Divisória por J.S.F. Hermes e Murillo de Miranda Bastos. Rio de Janeiro, Laemmert, 1940.

Holanda, Sérgio Buarque de. Visão do Paraíso. São Paulo, Nacional, 1977.

KIDDER, Daniel Parish. Reminiscências de Viagens e Permanência no Brasil: Província do Norte. Trad. Moacir de Vasconcelos. São Paulo, Martins, 1943.

Kloster, W. \& Sommer, F. Ulrico Schmidt no Brasil Quinhentista. Introdução de Francisco de Assis Carvalho Franco. Trad. G. A. Bucher. São Paulo, Tipografia Gutenberg, 1942.

Knivet, Anthony. Vária Fortuna e Estranhos Fados. Trad. Guimar de Carvalho Franco. 
São Paulo, Brasiliense, 1947. Coleção A Conquista da Terra, vol 5.

Koseritz, Carl von. Imagens do Brasil. Belo Horizonte/São Paulo, Itatiaia/Edusp, 1980. Coleção Reconquista do Brasil, 22.

Koster, Henry. Viagens ao Nordeste do Brasil. Tradução e notas de Luis da Câmara Cascudo. São Paulo, Nacional, 1942.

Lederc, Max. Cartas do Brasil. Trad. Sergio Milliet. São Paulo, Nacional, 1942.

LeIte, Serafim. A Companhia de Jesus no Brasil e a Restauração de Portugal; Pelo Acadêmico Titular Serafim Leite. Lisboa, Academia Portuguesa de História, 1942. (Separata dos Anais, VII). . As Primeiras Cartas dos Jesuítas do Brasil Para o Conhecimento da América: 1549-1562. Genova, Civico Instituto Colombiano, 1951. (Separata do vol. II do Studi Colombiani). . Cartas dos Primeiros Jesuítas do Brasil: 1538-1563. São Paulo, Comissão do Iv Centenário da Cidade de São Paulo, 1954. 3 vols. . História da Companhia de Jesus no Brasil. Lisboa, Portugália, 1938-1950, 10 vols. . Novas Cartas Jesuíticas: de Nóbrega a Vieira. São Paulo, Nacional, 1940.

Página de História do Brasil. São Paulo, s.d.

Suma História da Companhia de Jesus no Brasil: Assist. de Portugal, 1549-1766; por Serafim Leite. Lisboa, Junta de Investigação do Ultramar, 1965, xv.

LENKo, Karol. Insetos no Folclore por Karol Lenko e Nelson Papavero. São Paulo, 1979. Coleção Folclore, vol. 18.

LÉRY, Jean de. Histoire d'Un Voyage Faict en la Terre du Brèsil. Paris, A. Lemerre, 1880, 2 vols. . Histoire d'Un Voyage Fait en la Terre du Brèsil (1556-1558). Paris, Payot, 1927. História de uma Viagem Feita à Terra do Brasil. Tradução ordenada literiariamente por Monteiro Lobato. Rio de Janeiro/São Paulo, Nacional, 1926. Journal de Bord de Jean de Léry en la Terre du Brèsil, 1577; Presenté et Commenté par M.R. Mayeux. Paris, Editions de Paris, c. 1957. . Le Voyage au Brésil de Jean de Léry: 1556-1558, Avec une Introduction par Charly Clerc. Paris, Payot, 1927.

. Viagem à Terra do Brasil. Belo Horizonte/São Paulo, Itatiaia/Edusp, 1980. Coleção Reconquista do Brasil, vol. 10.

. Viagem à Terra do Brasil; Tradução Integral e Notas de Sergio Milliet, Segundo a Edição de Paul Gaffarel com o Colóquio na Língua Brasilica e Notas Tupinológicas de Plinio Airosa. $2^{\circ}$ ed, São Paulo, Martins, 1951. Coleção Biblioteca Histórica Brasileira, vol. 7.

Madureira, José Manuel de. A Liberdade dos Índios, A Companhia de Jesus, Sua Pedagogia e Seus Resultados. Rio de Janeiro, Imprensa Nacional, 1927-1929, 2 vols. . A Companhia de Jesus e o Brasil. (Separata do Anuário Catholico). (Publicado com: Pero Vaz de Caminha e a Carta do Achamento do Brasil, por Manuel de Sousa Pinto). Rio de Janeiro, Anuário do Brasil, 1924.

Magalhães, Basílio de. Expansão Geográfica do Brasil Colonial. São Paulo, Nacional, 1935.

Magalhães, José Vieira Couto de. Contes Indiens du Brèsil, Recuillis par M. de Général Couto de Magalhães et Traduits par Emile Allain. Rio de Janeiro, Lombaerts, 1882, vi. Primeira Viagem ao Araguaya; Escripta e Publicada em 1863. São Paulo, Typ. do "Federalista", 1889.

Marchant, Alexander. Do Escambo à Escravidão: As Relações Econômicas de Portugueses e Índios na Colonização do Brasil, 1500-1580. São Paulo, Nacional, 1943.

MARTIUs, Carl Friedrich Phil. von. Beiträge zur Ethnographie und Sprachenhude Amerika's Zumal Brasiliens. Leipzig, Friedrich Fleicher, 1897, 2 vols.

. Natureza, Doenças, Medicina e Remédios dos Índios Brasileiros: 1844. Tradução, Prefácio e Notas de Pirajá da Silva. São Paulo, Editora Nacional, 1939, xxxir.

Morais, Alexandre José de Mello. Corographia Histórica, Chronográphica, Nobiliana e Política do Império do Brasil Contendo Noções Históricas e Políticas, a Começar do Descobrimento da América e Particularmente do Brasil. Rio de Janeiro, Typ. Americana, 1858, 4 vols.

Morais, Raymundo. Paiz das Pedras Verdes, 2ª ed, Rio de Janeiro, Civilização Brasileira, 1931. Moreno, Diogo de Campos. Livro que dá Razão do Estado do Brasil. Edição Comemorativa do $\mathrm{V}$ 
Centenário de Pedro Alvares Cabral. Manuscrito do Séc. XviI, Conservado no Instituto Histórico e Geográfico Brasileiro. Cartografia atribuída a João Teixeira Albernaz I. Rio de Janeiro, Instituto Nacional do Livro, 1968.

MuccI, Alfredo. Acauã; Alguns Aspectos Morfocromáticos do Medo e Ansiedade no Fabulário Popular Brasileiro. São Paulo, Morumbi, 1977.

Nascimento, Bráulio do (org.). Bibliografia do Folclore Brasileiro; Organizado por Bráulio do Nascimento, Colaboração de Cydnéa Bouyer. Rio de Janeiro, Biblioteca Nacional, 1971. Coleção Rodolfo Garcia. Série B - Catálogos e Bibliografias.

NASH, Roy. A Conquista do Brasil. Trad. Moacyr N. Vasconcellos. São Paulo, Nacional, 1939.

Nieuhof, Joan. Memorável Viagem Marítima e Terrestre ao Brasil. Trad. Moacir N. de Vasconcelos. Introdução e notas por José Honório Rodrigues. São Paulo, Livraria Martins, 1942, XX.

Nimuendaju, Curt. Os Índios Parintins do Rio da Madeira. Paris, Société des Americanistes de Paris, 1924, (Separata: Journal de la Société des Americanistes de Paris, n.s. T.16, 1924, pp. 210-278).

NóBREGA, Manoel da. Cartas do Brasil, 1549-1560. Coleção Materiais e Achegas para a História e Geografia do Brasil, vol. 2. Edição fac-similar. Rio de Janeiro, Imprensa Nacional, 1886. Diálogo Sobre a Conversão do Gentio; Preliminares e Anotações Históricas e Críticas de Serafim Leite. São Paulo, Comissão do Iv Centenário da Cidade de São Paulo, 1954. Coleção Iv Centenário da Cidade de São Paulo, vol. 1.

PALHA, Frei Luiz. Índios Curiosos: Lendas, Costumes e Língua. Rio de Janeiro, 1942, 1 vol. REIS FilHo, Nestor Goulart. Catálogo de Iconografia das Vilas e Cidades do Brasil Colonial: 1500 - 1720. São Paulo, Faculdade de Arquitetura, 1964.

ReyBand, Joseph Charles. La Colonisation du Brèsil: Documents Officiels. Paris, Bourdier, 1858. . Le Brèsil. Paris, Guillarmin et Cie. Editeurs, 1856.

Ribeyrolles, Charles. Brasil Pitoresco, História, Descrições, Viagens, Colonização, Instituições. Ilustrado por Victor Frond. Trad. Gastão Penha. São Paulo, Martins, 1941, 3 tomos em 2 vols. Coleção da Biblioteca Histórica Brasileira, vol. 6.

RichSHOFfer, Ambrosio. Diário de um Soldado da Companhia das Indias Occidentaes:1629-1632; Traduzido do Rarissimo Original Allemão Annotado por Alfredo de Carvalho. Recife, Typ. a vapor de Laemmert \& Comp., 1897, viıI. Coleção História de Pernambuco, vol. 1.

Rodrigues, Pedro. Vida do Padre José de Anchieta. (Encadernado com: Cartas Inéditas do Padre José de Anchieta). Bahia, s.c.p.,1897.

RugendAs, João Maurício. Viagem Pitoresca Através do Brasil. Tradução de Sergio Milliet. $8^{a}$ ed, Belo Horizonte/São Paulo, Itatiaia/Edusp, 1979. Coleção Reconquista do Brasil, vol. 2.

Rugendas, Johann Moritz. Paisagem Colonial. Por Rugendas e J.B. Debret, litografias e textos reproduzidas da edição original Voyage Pittoresque au Brèsil, editada em 1834, em Paris; trad. e adaptação de Sergio Milliet, prefácio de Arnaldo d'Avila Florence. São Paulo, Difusão nacional do livro, s.d. Coleção Documentos Históricos, vol. 7.

Saint Hilaire, Auguste de. Viagem à Província de São Paulo e Resumo das Viagens ao Brasil, Província Cisplatina e Missões do Paraguay. Trad. Rubens Borba de Morais. $2^{\mathrm{a}}$ ed, São Paulo, Martins, 1945. Coleção Biblioteca Histórica Brasileira, vol. 2.

SALVAdor, Vicente do. História do Brasil. Edição revista por Capistrano de Abreu. São Paulo, Melhoramentos, 1918. xxxv.

História do Brasil. Rio de Janeiro, Leuzinger/Biblioteca Nacional, 1889. xx.

SAmpaIo, Theodoro Fernandes. O Rio São Francisco e a Chapada Diamantina: Trechos de Um Diário de Viagem. São Paulo, Escolas Profissionaes Salesianas, 1905.

SAmpaio, Theodoro \& Teschauer, Carlos. Os Naturalistas Viajantes dos Séculos XVIII e XIX e a Etnografia Indígena. Salvador, Progresso, 1955.

SAntos, Yolanda Lhullier dos. A Imagem do Índio na Ficção do Paraíso. São Paulo, Departamento de Ciências Sociais, FFLCH-USP, 1972. Tese de doutorado.

Schaden, Egon. A Mitologia Heróica de Tribos Indígenas do Brasil: Ensaio Etno-Sociológico. Rio de Janeiro, Ministério de Educação e Cultura/Serviço de Documentação, 1959. Coleção Vida Brasileira, vol. 15. 
Schmidel, Ulrich. Voyages Relations et Mémoires Originaux Pour Servir a l'Histoire de la Decouverte de l'Amerique; Publiés Pour la Premiere Fois en Français, par H. TernouxCompans. Paris, Arthur Bertrand, 1837. viII.

SEIDLER, Carl. Dez Anos de Brasil. Belo Horizonte/São Paulo, Itatiaia/Edusp, 1980. Coleção Reconquista do Brasil, vol. 24.

Simpósıo de Pesquisa de Folclore, $1^{\circ}$. Arquivo do Estado de São Paulo.

Simpósio de Pesquisa de Folclore, 2․ Arquivo do Estado de São Paulo.

SOARES, José Carlos de Macedo. Fronteiras do Brasil no Regime Colonial. Ilustração de mapas de J.Wasth Rodrigues. Rio de Janeiro, José Olympio, 1939. Coleção Documentos Brasileiros, vol. 19.

SousA, Gabriel de Soares. Derrotero General de la Costa del Brasil y Memorial de las Grandezas de Bahia: Manuscrito del Siglo Xvi. Introdução de Cláudio Ganns. Notas finais de F. A. de Varnhagen. Madrid, Cultura Hispanica, 1958. xxxiII.

. Notícias do Brasil. Comentários e notas de Varnhagen, Pirajá da Silva e Edelweiss.

São Paulo, Revista dos Tribunais, 1974. Coleção Brasiliensia Documenta, vol. 7

Notícias do Brasil. Introdução, comentários e notas pelo professor Pirajá da Silva.

São Paulo, Martins, s.d, 2 vols. Coleção Biblioteca Histórica Brasileira, vol. 16.

. Tratado Descriptivo do Brasil em 1587. 3ª ed. São Paulo, Ed. Nacional, 1938.

Tratado Descritivo do Brasil em 1587. [Edição castigada pelo estudo e exame

de muitos códices manuscritos existentes no Brasil, em Portugal, Espanha e França,

e acrescentada de alguns comentários por Francisco Adolfo de Varnhagen]. 4를.

São Paulo, Ed. Nacional, 1971.

SouzA, Bernardino José de. Dicionário da Terra e da Gente do Brasil. $5^{\text {a }}$ ed. São Paulo, Nacional, 1961.

SpIX, Johann Baptist von \& MARTius, Carl Friedrich Phillip von. Viagem Pelo Brasil.

Rio de Janeiro, Imprensa Nacional, 1938, 4 vols.

Staden, Hans. Duas Viagens ao Brasil. Belo Horizonte/São Paulo, Itatiaia/Edusp, 1974. Duas Viagens ao Brasil: 1547-1555. São Paulo, Gutenberg, 1942.

. Primeiro Viajante. Prefácio e legendas adaptadas por Jamil Almansur Haddad, gravuras de Leo Theodorum de Bry, reproduzidas da edição original de 1557 em Marburgo, Alemanha. São Paulo, Difusão Nacional do livro, s.d. Coleção Documentos históricos, vol. 1.

Suas Viagens e Cativeiro Entre os Índios do Brasil. Texto ordenado por Monteiro Lobato. 4 a . ed. São Paulo, Nacional, 1945. Biblioteca do Espírito Moderno. Série 3a ${ }^{\text {a }}$ História e Biografia, vol. 39 .

. Vera Historia y Descripción de un País de las Salvajes Desnudas Feroces Gentes Devoradoras de Hombres Situado en el Nuevo Mundo América. Buenos Aires, Coni, 1944.

. Viagem ao Brasil. Salvador, Progresso Editora, 1955. Coleção Estudos Brasileiros. Série Cruzeiro, vol. 10

. Suas Viagens e Cativeiro Entre os Selvagens do Brasil. [Traduzida da primeira edição original com anotações explicativas]. São Paulo, Typ. da Casa Eclectica, 1900, 1 vol.

TAUnAY, Affonso d'Escragnolle. História Geral das Bandeiras Paulistas Escriptas à vista de Avultada Documentação Inédita dos Archivos Brasileiros, Hespanhoes e Portuguezes. São Paulo, Typ. Ideal, 1924, 11 vols. Zoologia Fantástica do Brasil. São Paulo, Melhoramentos, s.d.

TORRES, Luis Wanderley. Nordeste Pitoresco e Engraçado. 2ª ed. s.l., Ulpiano, 1980.

Varnhagen, Francisco Adolfo de, Visconde de Porto Seguro. Examen de Quelques Points de l'Histoire Geographique du Brèsil, ou, Analyses Critique du Rapport de M. de Avezac sur la Recente Histoire Général du Brèsil, par mr. F. A. de Varnhagen. Paris, Imprimierie de L. Martinet, 1858.

O Descobrimento do Brasil, Chrônica do fim do Décimo Quinto Século; Segunda Edição Autêntica, Revista, Correcta e Acrescentada Pelo Autor. Rio de Janeiro, Typ. Imp. e Const. de J. Villeneuve e Comp., 1840.

VASCONCELlos, Simão de. Chrônica da Companhia de Jesus do Estado do Brasil. $2^{\mathrm{a}}$ ed. Lisboa, Fernandes Lopes, 1865. CLVI

VieIRA, Antonio. Cartas do Padre Antonio Vieira, Coordenadas e Anotadas por J. Lucio d'Azevedo. Biblioteca de Escritores Portugueses. Série C. Coimbra, Universidade, 1925-1926, 1928, 3 vols. Biblioteca de Escritores Portugueses. Série C.

. Padre Antônio Vieira: Sermões Pregados no Brasil. Seleção e ordenação, prefácio e notas por Hernani Cidade. 2ª ed. Lisboa, Agência Geral das Colônias, 1940, 4 vols. 
. Por Brasil e Portugal. Sermões comentados por Pedro Calmon. São Paulo, Nacional, 1938.

Wallace, Alfred Russel. Viagens pelo Amazonas e Rio Negro. Trad. Orlando Torres. São Paulo, Nacional, 1939.

Ananás. THEVET, André. Singularidades da França Antarctica, 1944, p. 281. 